\title{
Ecological impact evaluation of urban heat island in Dhaka city; a spatio-temporal approach
}

\section{Kazi Jihadur Rashid}

University of Chittagong Faculty of Biological Science

Sumaia Islam

University of Chittagong

Mohammad Atiqur Rahman ( $\nabla$ mmd.atiqur.rahman@gmail.com )

University of Chittagong Faculty of Biological Science https://orcid.org/0000-0002-7198-4399

\section{Research Article}

Keywords: Dhaka city, Ecological Evaluation Index, LST Trajectory, UHI, UTFVI

Posted Date: August 31st, 2021

DOI: https://doi.org/10.21203/rs.3.rs-307151/v1

License: (c) (i) This work is licensed under a Creative Commons Attribution 4.0 International License.

Read Full License 
1 Ecological impact evaluation of urban heat island in Dhaka city: A spatio-temporal approach

\section{Abstract}

4 Urban heat island (UHI) is one of the major causes for deteriorating ecology of the

5 rapidly expanding Dhaka city in the changing climatic conditions. Although researchers

6 have identified, characterized and modeled UHI in the study area, the ecological

7 evaluation of UHI effect has not yet been focused. This study uses land surface

8 normalization techniques such as urban thermal field variance (UTFVI) to quantify the

9 impact of UHI and also identifies vulnerable UHI areas compared to land cover types.

10 Landsat imageries from 1990 to 2020 were used at decadal intervals. Results of the study

11 primarily show that intensified UHI areas have increased spatially from $33.1 \%$ to $40.9 \%$

12 in response to urban growth throughout the period of 1990 to 2020. Extreme surface

13 temperature values above $31^{\circ} \mathrm{C}$ have also been shown in open soils in under-construction

14 sites for future developmental purposes. UTFVI is categorized into six categories

15 representing UHI intensity in relation to ecological conditions. Finally, comparative

16 analysis between land use/land cover (LULC) with UTFVI shows that the ecological

17 conditions deteriorate as the intensity of UHI increases in the area. The developed areas

18 facing ecological threat have increased from $9.3 \%$ to $19.8 \%$ throughout the period.

19 Effective mitigating measures such as increasing green surfaces and planned urbanization

20 practices are crucial in this regard. This study would help policymakers to concentrate on

21 controlling thermal exposure and on preserving sustainable urban life.

22 Keywords Dhaka city; Ecological Evaluation Index; LST Trajectory; UHI; UTFVI

\section{Introduction}

24 Urbanization causes radiation balance alteration that triggers variations in reflective 25 power (Shahmohamadi et al. 2011). The resultant effect makes urban areas warmer than

26 their surrounding countryside. This phenomenon of fluctuating temperatures is known as

27 the Urban Heat Island (UHI) (Oke 1982; Toy and Yilmaz 2010; Stewart and Oke 2012).

28 Notwithstanding the sizes, each urban structure can generate UHI of 0.4 to $11^{\circ} \mathrm{C}$ hotter

29 than the adjacent suburban areas (Oke 1973; Tzavali 2015). The development of UHI is 
30 fueled by the dynamic interaction of various factors. These factors can generally be

31 asserted as anthropogenic heat, impermeable surfaces, and geometry of urban structures

32 (Ryu and Baik 2012; Li et al. 2020). Recent decades have seen threatening impacts of

33 UHI on the human environment (Watkins et al. 2007; Yow 2007; Ward et al. 2016). Yow

34 (2007) discussed local to global impacts of UHI including human health and comfort,

35 energy consumption, alterations in ecosystems, and climate. For instance, urban warming

36 with changing climate effects on fish communities as well as trophic dynamics of water

37 bodies results in degrading ecological status of the ecosystem (Jeppesen et al. 2010,

38 Pörtner and Peck 2010).

39 Urban regions that facilitate human society to develop seamlessly but also jeopardize the

40 quality of the environment and ecosystem as well. Degradation of the environmental

41 quality increases various diseases and mortality as well as hampers urban productivity

42 (Arnfield 2003; Grimm et al. 2008; Zhou et al. 2014; Zhou et al. 2016). Therefore,

43 contemporary urban researchers are focusing on alleviating and reducing UHI ( $\mathrm{Li}$ et al.

44 2014; O'Malley et al. 2015; He et al. 2019).

45 In recent times, the UHI effect can be measured by several methods. Among them,

46 surface UHI assessment by using satellite data is a significant and most recommended

47 method (Voogt and Oke 2003). The surface temperature that emits from land and detects

48 by satellite can play a key role in the age of UHI as a crucial variable (Zhou et al. 2019)

49 in terms of surface radiation and energy transactions. It regulates the circulation of warm

50 air between the surface and the atmosphere. Until now Land Surface Temperature (LST)

51 has been calculated by several algorithms (e.g. Planck Function, Single Channel

52 Algorithm) which are developed in recent times ( $\mathrm{Li}$ et al. 2013; Avdan \& Jovanovska

53 2016; Ndossi \& Avdan 2016; Sahana et al. 2016) . Ndossi \& Avdan (2016) compared

54 different algorithms for LST derivation and found that Planck Function produces the best

55 outcomes on both Landsat 05 and Landsat 08. LST normalization indices such as urban

56 thermal field variance (UTFVI) help to better evaluate urban thermal intensities and

57 ecological health (Guha et al. 2018). For maintaining the environmental balance within a

58 city, determining the level of ecological comfort is an important task.

59 Dhaka is the most populated city in Bangladesh experiencing the fastest urbanization

60 within the world unlike other less developed and developing countries (Seto et al. 2011). 
61 Several attempts have been made to investigate UHI in the city using air temperature, 62 surface temperature from satellite sensor, numerical modeling (Ahmed et al. 2013; Das \& 63 Karmakar 2015; Tashnim \& Anwar 2016). Das \& Karmakar (2015) analyzed the annual 64 temperature data from 1961 to 2000 and also studied the Weather Research and 65 Forecasting (WRF) model, which showed a growing trend of temperature in the city 66 compared to the surrounding districts and found that it was mostly warm during the night 67 and afternoon hours. Kakon \& Nobuo (2009) investigated the effect of sky view factor on 68 seasonal solar radiation in the study area. Previous studies on UHI in the study area were 69 mainly focused on UHI intensity, factors, and the correlation of different land cover types 70 with LST (Raja 2012; Dewan \& Corner 2014; Mia et al. 2017; Trotter et al. 2017;

71 Rahman et al. 2020). However, much of the research evaluating the impact of UHI up to 72 now in the city has been descriptive and no prior studies have been undertaken to assess 73 the impact of UHI quantitatively.

74 To address the research gap mentioned above, this study focuses mainly on the spatial75 temporal assessment of the impact of UHI on the urban ecosystem over the study area 76 using Landsat images through the period from 1990 to 2020. First, this study analyzes the 77 spatial-temporal variations of LST. Secondly, the study explores the surface cover 78 scenarios and the UHI affected area. Finally, quantitatively evaluates the ecological 79 impact of UHI using the UTFVI. 


\section{$81 \quad 2.1$ Study area}

82 The study area, Dhaka is shown in Fig. 1. It is positioned in central Bangladesh at

$8323^{\circ} 42^{\prime} \mathrm{N}$ and $90^{\circ} 22^{\prime} \mathrm{E}$. The city has a population of 21,005,860 (2020) approximately with

84 a total area of $306 \mathrm{~km} 2$. The city is located on the lower range of the Ganges Delta which

85 is flat and close to sea level and the land is characterized by tropical vegetation and moist

86 soils under the Köppen climate classification. Dhaka experiences a mean annual rainfall

87 of 2,084.7 millimeters and an average annual temperature of $25.9^{\circ} \mathrm{C}$ varying between

$8818.6^{\circ} \mathrm{C}$ in January and $29{ }^{\circ} \mathrm{C}$ in June which resembles a tropical savanna climate

89 (Choudhury 2016).

\section{$90 \quad 2.2$ Data}

91 Landsat TM (1990, 2000, and 2010) and Landsat OLI/TIRS (2020) were downloaded

92 from the official website of the US Geological Survey (USGS). Spatial resolution of

93 Landsat is 30 meter and images for the study area fall inside the scene of path 137 and

94 row 44. Cloud free images of winter were collected to have similar weather conditions

95 and phenological characteristics. Table 1 illustrates collected data in detail.

\section{$96 \quad 2.3$ Methodology}

97 All the following procedures were carried out using QGIS software and R programming. 98 Image correction and sampling for LULC were done in QGIS platform. Image

99 classification, LST calculation, and visualization were performed in Rstudio with the help 100 of raster, rgdal, caret packages.

\section{2.3.1 Data processing}

102 Prior to analysis of Landsat imageries, radiometric calibration and atmospheric correction 103 are necessary. All the collected raw bands were converted into top of atmosphere (TOA) 104 reflectance and radiance from digital numbers (DN) to represent physical properties 105 (Yankovich et al. 2019). The DOS1 method was applied to correct atmospheric 
106 disturbances. Resultant surface reflectance and brightness temperature $(\mathrm{K})$ bands were

107 then used in the further calculation of LST $\left({ }^{\circ} \mathrm{C}\right)$, and LULC retrieval.

$108 \quad$ 2.3.2 LST retrieval

109 LST was derived from the brightness temperature of band 06 and 10 of Landsat TM and

110 TIRS respectively. Corrected near-infrared (NIR) and Red bands were used to calculate

111 NDVI. It is calculated by dividing the differences between NIR and Red with their sum to

112 correct brightness temperature against land surface emissivity. The NDVI threshold

113 method was applied to estimate surface emissivity. The proportion of vegetation (Pv) was

114 determined using the following equation1 (Carlson and Ripley 1997).

$$
P v=\left[\frac{(N D V I-N D V I s)}{(N D V I v-N D V I s)}\right]^{2}
$$

115 Where, NDVIs and NDVIv is the value assigned for bare soil (0.2), and healthy 116 vegetation (0.5) respectively.

117 It is essential to obtain surface emissivity for accurate measurement of LST since it is a 118 proportionality factor that scales blackbody radiance (Planck's law) and predict radiance 119 (Jiménez-Muñoz et al. 2006). The emissivity was conditionally determined (Wang et al. 120 2015) from equation (2).

$$
\varepsilon=\varepsilon_{v} P_{v}+\varepsilon_{s}\left(1-P_{v}\right)+C
$$

121 Where, $\varepsilon v$ is vegetation emissivity, $\varepsilon s$ is soil emissivity and $\mathrm{C}$ represents the cavity effect 122 of the surface ( $\mathrm{C}=0$ for flat surfaces) was estimated using equation (3)

$$
C=\left(1-\varepsilon_{s}\right)\left(1-P_{v}\right) F \varepsilon_{v}
$$

123 Where, $\mathrm{F}$ is a shape factor, whose mean value is 0.55 assuming different geometrical 124 distributions (Sobrino et al. 2004) in the area.

125 For TIRS band 10, when the NDVI is less than 0 , the emissivity value of 0.991 is 126 assigned considering pixels as water. For values between 0 and 0.2 , the emissivity value 127 of 0.966 is assigned considering pixels as soil. For values between 0.2 and 0.5 , equation 
128 (2) is applied to retrieve the emissivity considering pixels as mixtures of vegetation and 129 soil. At last, when the NDVI value is greater than 0.5 , the value 0.973 is assigned 130 considering pixels to be covered with vegetation.

131 For TM band 06, simplified equation (4) is used to determine emissivity (Sobrino et al. 132 2004).

$$
\varepsilon=0.004 P v+0.986
$$

133 Finally, the emissivity correction of LST was carried out using the following equation (5) 134 (Avdan \& Jovanovska 2016).

$$
T_{s}=\frac{B T}{\left\{1+\left[\frac{\lambda \sigma B T}{h c}\right] \cdot \operatorname{ln\varepsilon }\right\}}-273.15
$$

135 Where, Ts is the $\operatorname{LST}\left({ }^{\circ} \mathrm{C}\right), \mathrm{BT}$ is at-sensor brightness temperature $(\mathrm{K}), \lambda$ is the effective 136 wavelength of the radiance, $\sigma$ is Boltzmann constant $(1.38 \times 10-23 \mathrm{~J} / \mathrm{K}), \mathrm{h}$ is Planck's 137 constant $(6.626 \times 10-34 \mathrm{Js}), \mathrm{c}$ is the velocity of light in a vacuum $(2.998 \times 10-8 \mathrm{~m} / \mathrm{sec})$ 138 and $\varepsilon$ is emissivity.

\section{$139 \quad 2.3 .3$ UTFVI calculation}

140 Several indices of thermal comfort are available for assessing the UHI impacts on the 141 quality of urban life (Ahmed 2018; Guha et al. 2018). UTFVI was calculated for

142 quantitative evaluation of the impact of UHI using equation (6) and divided into six 143 levels corresponding to ecological evaluation indices and UHI phenomenon intensity 144 shown in Table 5 (Guha et al. 2018).

$$
U T F V I=\frac{T s-T m}{T m}
$$

145 Where Ts and $\operatorname{Tm}$ are $\operatorname{LST}\left({ }^{\circ} \mathrm{C}\right)$ and mean $\operatorname{LST}\left({ }^{\circ} \mathrm{C}\right)$ respectively.

$146 \quad$ 2.3.4 LULC classification

147 There have been many classification algorithms developed and implemented to classify 148 images. Machine learning (ML) classifiers (e.g., random forest, support vector machine)

149 is being popular for their high accuracy and robustness (Zhu \& Woodcock 2014; Belgiu 
150 and Drăguţ 2016). For this study, Random forest (RF) was used to LULC classification of

1514 different years according to the classification scheme of Table 2. RF is a non-

152 parametric ML algorithm, can handle high dimensional data (Gislason et al. 2006). It is

153 an ensemble of decision trees which are trained on bootstrapped samples of original

154 training datasets. For classification, each tree provides a class-label and the output is

155 determined by the mostly voted class of the trees. In RF, two-third of the training samples

156 are used to classify and another one-third is considered as out-of-bag (OOB) data. These

157 OOB data are then used to produce a non-biased measurement of the error rate of 158 classification (Breiman 2001).

\section{$159 \quad 3$ Result}

\section{$160 \quad 3.1$ LST Trajectory}

161 Before conducting any kind of application procedure, validation of extracted LST is 162 essential with in situ observations or with another kind of satellite sensor. In this research, 163 air temperature data were collected from different sources for the study area. Air 164 temperature and LST of similar dates were compared and validated. The range of LST of 165 the study area closely approximates with the air temperature of that area. The spatial 166 extent and magnitude of LST have become more salient during 2020 from the past. 167 Spatial distribution and descriptive statistics of LST of the corresponding year is 168 represented in Table 3 and Fig. 2. A significant increase in the mean and maximum LST 169 was followed between 2000 and 2020 . Around $75 \%$ of the area had a temperature of over $17018^{\circ} \mathrm{C}$ in 1990 and decreased to closely $50 \%$ in 2000 . More than $75 \%$ area in 2020 was 171 occupied by temperatures above $22^{\circ} \mathrm{C}$ (Table 3). It is apparent from the table that LST of 172 the previous decade (1990-2000) was less deviated from the mean value which shows 173 more variability in the recent decade (2010-2020). The lower central regions were 174 relatively higher than the surroundings during 1990 and 2000. Peripheral areas have 175 shown a decrease in LST from 1990 to 2000. In the years 2010 and 2020, some patches 176 of extreme LST have been noticed in peripheral areas. Apart from that, a denser and high 177 LST distribution can also be seen in the central zone (Fig. 2).

\subsection{UHI identification}


179 Validation of LULC classifications (1990 - 2020) involved collecting samples from high180 resolution images of the closest dates available of Google Earth. Because of the 181 unavailability of Google Earth's image during 1990 samples were collected from the 182 corrected Landsat image of the year. Overall accuracy was achieved for all the 183 classifications ranging from 94 to $96.2 \%$ with kappa accuracy ranging from 92 to $95 \%$.

184 It can be seen from Fig. 3 that urban expansion took place in all directions. Noticeable 185 expansion of urban areas has occurred northward and southeastward direction. A

186 comparison of the LULC area and corresponding LST data between 1990 and 2020 is 187 presented in Table 4. The developed surface dramatically increased throughout the period. 188 The water surface showed a significant decline after 2000 followed by a moderate 189 increase from 1990. Open soil decreased by 50\% between 1990 and 2010 and 190 significantly expanded afterwards.

191 Differences in mean LST of the developed surface to others are displayed in Fig. 4. The 192 mean LST of the developed surface is higher than other classes supporting the existence 193 of UHI. Open soil in 2010 and 2020 exhibits higher mean LST than developed areas and 194 showed high variability than other classes from in both the years' Table 4. The reason 195 behind this variability can be the contrasting nature of open soils in the study area. Open 196 soil surfaces show an almost similar temperature to developed surfaces. In our study area, 197 identified patches of open soil in Fig. 5 gives a close look to the corresponding surface in 198 high resolution of Google Earth imagery. These surfaces are cleared bare soils for 199 development purposes. These soils are drier than other barren surfaces of the study area 200 which are mostly low lying lands.

\section{$201 \quad 3.3$ UHI evaluation}

202 UTFVI classification and relevant statistics are shown in Fig. 6 and Table 5 for 203 comparative evaluation of the UHI impact over decades. Most of the regions were 204 occupied with the strongest UHI $(>0.020)$ and none UHI $(<0)$. Strongest UHI spread 205 spatially over time in upper eastern and southern regions (Fig. 6). Strongest UHI 206 experienced in the study area showed a steady increase until 2010. In 2020, the strongest 
207 UHI decreased from the previous year and showed the presence of strong and stronger 208 classes of the UHI phenomenon.

209 According to the Ecological Evaluation Index (EEI), conditions ranging from bad to 210 worst considerably increased, and above normal conditions showed a decline in contrast

211 (Table 5). Ecological conditions ranging from bad to worst in the developed area showed 212 progressive trends throughout the period whereas similar conditions in the non-developed 213 area were regressive until 2010 and increased afterwards (Table 6). Figure 7 shows 214 ecologically threatened developed surfaces in red color.

\section{Discussion}

216 The findings of the study show that the total environmental scenario of Dhaka was 217 degraded in the developed area from 1990 to 2020 due to urban expansion as well as UHI 218 intensification. Below normal ecological conditions showed considerable increase 219 throughout the period, albeit the city central zone experiencing low UHI effect and 220 having a normal ecological condition in 2020 (Fig. 6). There has not been an increase of 221 vegetated or water surface in that zone to reduce the temperature and the rooftop garden 222 is not extensively used (Farhana et al. 2019) which can mitigate the UHI effect. Therefore,

223 the possible reason could be extreme heated open soils in surrounding patches shown in 224 Fig. 6 influencing the LST normalization. Similar to Raja (2012), some open soil patches 225 in adjacent urban areas show the highest LST in the years 2010 and 2020. These are the 226 cleared or filled sites for new urban extensions (Fig. 5).

227 Highly centralized movement of people, along with an increase in urban population by 228 birth increases pressure in cities. Dhaka receives 300,000 to 400,000 migrants annually 229 for economic opportunities and other urban facilities (Lata 2017). This human pressure is 230 the determinant of city expansion, both vertically and horizontally. Besides, the 231 increasing concentration of the population in a particular region adversely affects the 232 exploitation of the natural resources of the region (Rashid 2020). In response to its 233 growth, the city is opening up new opportunities and facilities. This vicious nature of city 234 dynamics keeps urban temperatures rising more frequently than the surrounding 235 counterpart and constantly entraps city dwellers inside the UHI bubble. It is evident from 
236 this study as well as previous literature (Ahmed et al. 2013; Dewan \& Corner 2014) that 237 developed surfaces along open dry soils release higher LST than other surface types 238 (Table 4). With the rising temperature, energy demand also increases for cooling the 239 building's inside environment and puts pressure on the electricity grid during peak hours. 240 Uses of air cooler, refrigerator, etc. contribute to greenhouse gas volume which 241 ultimately warms the earth (Calm 2002) and creates discomfort for us. Industrial 242 chemicals, gashes, and contaminants create several environmental problems by 243 modifying natural substances, create human health nuisance, and hamper an imbalance in 244 biodiversity. In developing countries, the share of emitting greenhouse gases from urban 245 areas is increasing rapidly. It is threatening for the urban dwellers' health; particularly the 246 poor urban dwellers are in vulnerable conditions due to the newly created health hazards 247 imposed by modified urban climate and a brief consideration of climate change (Oke 248 1982; Toy and Yilmaz 2010). Besides, due to the increasing trend of UHI and the 249 influence of climate change, urban areas are more prone to undergo environmental 250 hazards than their rural counterparts (Fig. 2). An approximate estimation of urban 251 population facing below normal ecological conditions is 595,862.73 (9.3\%) in 1990 252 which increased to 4,201,172 (19.8\%) in 2020 (Fig. 7). Heat-related mortality and illness 253 also increase with the rising temperature ( $\mathrm{Wu}$ et al. 2018). The sensitive population 254 especially children and older people of the city are more vulnerable to heat-initiated 255 diseases (McMichael et al. 2008). On the contrary, the less intense winter season 256 decreases the rate of cold-induced death. But in urban areas, hot microclimate also 257 damages the atmospheric layer and produces an increasing amount of photochemical 258 smog (for example, ozone); thus health risks also increase. UHI also degrades the quality 259 of water sources in different ways. One of the foremost reasons is the heat-generating 260 wastages coming from industries and other urban sources. Runoff from urban areas is 261 hotter than the adjacent countryside in the summer season while the temperature of the 262 pavement is higher than the air temperature. Runoff with high-temperature causes 263 damage to young plants on its way and affect the ecosystem of water bodies and wetlands.

264 It is observed in association with Islam et al. (2010) that the water surfaces are declining. 265 Thus thermal alteration of water surfaces is adding to the problems already being faced 266 from the reduction of water occupied areas. Fish communities are much likely to change 
267 in growth, abundance, community structure, and richness due to this warming (Jeppesen 268 et al. 2010, Pörtner and Peck 2010). Pörtner and Peck (2010) discussed that thermal 269 tolerance varies among species and their life stages as well which in turn affects 270 ecosystem productivity.

271 The pressure on the ecosystems of the world is increasing due to the influential role of 272 urban inhabitants. As a result, cities have significantly large ecological footprints.

273 Urbanization also offers some ecological benefits, among them shared use of the resource,

274 opportunities for reuse and recycling and economies of scale are primes. To make 275 effective use of the urban ecosystem and produce most of the outcomes, it is necessary to 276 achieve a sustainable means of obtaining ecosystem services. Hence, UHI mitigation 277 practices need to be deployed as early as possible. Both nature-based solutions (i.e. 278 rooftop gardening, green spaces) and technical solutions (i.e. white rooftop, solar panel 279 on the roof) can be used to reduce the UHI effect. Residential areas can use rooftop 280 gardening to reduce heat and create spaces by applying the floor area ratio (FAR) for 281 more green cover (Mahtab-uz-Zaman et al. 2007). A newly built environment such as the 282 Basundhara Residential Area which is facing the worst case of heat stress must consider 283 these mitigating measures. The solar panel seems to be a viable solution for mitigating 284 UHI and energy consumption in industrial and commercial areas to an extent (Masson 285 2014).

\section{Conclusion}

287 Extensive urbanization factored by rapid population growth and economic development 288 impacting local climates in metropolitan areas. UHI is the boomerang effect of unplanned 289 urban development. Transformation of big cities into UHI is considered as one of the 290 most highlighted results of microclimate change. The purpose of the current study was to 291 determine the impact of UHI on the ecosystem of Dhaka city. This study has shown that 292 high UHI experienced area, as well as the worst ecological condition, is expanding 293 considerably in the city especially over the developed surfaces. The findings of this study 294 based on satellite remote sensing analysis generate valuable information regarding urban

295 health from the UHI mapping which can be used as an important reference for planners, 
296 stakeholders, policymakers to aid in the mitigation measures. Further research can be

297 carried out to assess the viability of the different mitigating solution and analyze the 298 thermal tolerance of the urban ecosystem components.

\section{Acknowledgements}

300 Authors are thankful to the Climatic Research Group (CRG), Department of Geography 301 and Environmental Studies, University of Chittagong for providing different sorts of

302 supports during the study.

\section{References}

304 Ahmed B, Kamruzzaman M, Zhu X, Rahman M, Choi K (2013) Simulating land cover 305 changes and their impacts on land surface temperature in Dhaka, Bangladesh. Remote 306 Sens 5(11):5969-5998 https://doi.org/10.3390/rs5115969

307 Ahmed S (2018) Assessment of urban heat islands and impact of climate change on 308 socioeconomic over Suez Governorate using remote sensing and GIS techniques. 309 $\begin{array}{lllll}\text { Egypt J Remote Sens } & \text { Space } & \text { Sci } & \text { 21(1):15-25 }\end{array}$

311 Arnfield AJ (2003) Two decades of urban climate research: a review of turbulence,

312 exchanges of energy and water, and the urban heat island. Int J Climatol 23(1):1-26

313 https://doi.org/10.1002/joc.859

314 Avdan U, Jovanovska G (2016) Algorithm for automated mapping of land surface 315 temperature using LANDSAT 8 satellite data. J Sens 2016:1-8 316 https://doi.org/10.1155/2016/1480307

317 Belgiu M, Drăguţ L (2016) Random forest in remote sensing: A review of applications 318 and future directions. ISPRS J Photogramm Remote Sens 114:24-31 319 https://doi.org/10.1016/j.isprsjprs.2016.01.011

320 Bivand R, Keitt T, Rowlingson B (2018) Bindings for the "Geospatial" Data Abstraction 321 Library $[\mathrm{R}$ Package Rgdal Version 0.8-13] https://CRAN.R322 project.org/package $=$ rgdal

323 Breiman L (2001) Random forests. Mach Learn 45(1):5-32 324 https://doi.org/10.1023/A:1010933404324 
325 Calm JM (2002) Emissions and environmental impacts from air-conditioning and

326 refrigeration systems. Int J Refrig 25(3):293-305 https://doi.org/10.1016/S0140$327 \quad 7007(01) 00067-6$

328 Carlson TN, Ripley DA (1997) On the relation between NDVI, fractional vegetation cover, and leaf area index. Remote Sens Environ 62(3):241-252 https://doi.org/10.1016/S0034-4257(97)00104-1

Choudhury AM (2016). Climate of Bangladesh. MET Report, 08/2016 ISSN 2387-4201, 159.

Das MK, Karmakar S (2015) Urban Heat Island Assessment for a Tropical Urban AirShed in Bangladesh. In: Proceedings of the 9th International Conference on Urban Climate jointly with 12th Symposium on the Urban Environment, France.

Dewan A, Corner R (2014) Impact of land use and land cover changes on urban land surface temperature. In: Dewan A, Corner R, eds. Dhaka Megacity. Springer Netherlands, pp 219-238 https://doi.org/10.1007/978-94-007-6735-5

Farhana F, Islam N, Zubayer S, Ahmed NU (2019) Green Roof: An approach to repair

342 Gislason PO, Benediktsson JA, Sveinsson JR (2006) Random Forests for land cover classification. Pattern Recognit

Lett 27(4):294-300 https://doi.org/10.1016/j.patrec.2005.08.011

Grimm NB, Faeth SH, Golubiewski NE, Redman CL, Wu J, Bai X, Briggs JM (2008) Global change and the ecology of cities. Science 319(5864):756-760 https://doi.org/10.1126/science.1150195

Guha S, Govil H, Dey A, Gill N (2018) Analytical study of land surface temperature with NDVI and NDBI using Landsat 8 OLI and TIRS data in Florence and Naples city,

355 Hijmans RJ (2016) Geographic Data Analysis and Modeling [R Package Raster Version 
Isaya Ndossi M, Avdan U (2016) Application of open source coding technologies in the 358 production of land surface temperature (LST) maps from Landsat: A PyQGIS plugin.

359 Remote Sens 8(5):413 https://doi.org/10.3390/rs8050413

360 Islam MS, Rahman MR, Shahabuddin AKM, Ahmed R (2010) Changes in wetlands in 361 Dhaka City: Trends and physico-environmental consequences. J Life Earth Sci 5:37$36242 \mathrm{https}: / /$ doi.org/10.1007/s10750-010-0171-5

363 Jeppesen E, Meerhoff M, Holmgren K, González-Bergonzoni I, Teixeira-de Mello F, 364 Declerck SA, De Meester L, Søndergaard M, Lauridsen TL, Bjerring R, Conde365 Porcuna JM (2010) Impacts of climate warming on lake fish community structure and 366 potential effects on ecosystem function. Hydrobiologia 646(1):73-90 https://doi.org/10.1007/s10750-010-0171-5

368 Jiménez-Muñoz JC, Sobrino JA, Gillespie A, Sabol D, Gustafson WT (2006) Improved 369 land surface emissivities over agricultural areas using ASTER NDVI. Remote Sens Environ 103(4):474-487 https://doi.org/10.1016/j.rse.2006.04.012

Kakon AN, Nobuo M (2009) The sky view factor effect on the microclimate of a city environment: A case study of Dhaka City. In: Proceedings of the 7th International Conference on Urban Climate, Yokohama, Japan (Vol. 29).

Kuhn M (2020) Classification and Regression Training [R Package Caret Version 6.0-86]. https://CRAN.R-project.org/package=caret

Lata LN (2017) Migration and Urban Livelihoods: A Translocal Perspective in Dhaka, Bangladesh. In: Conference Proceedings TASA 2017 Conference.

Li D, Bou-Zeid E, Oppenheimer M (2014) The effectiveness of cool and green roofs as urban heat island mitigation strategies. Environ Res Lett 9(5):055002 https://doi.org/10.1088/1748-9326/9/5/055002

Li Z-L, Si M, Leng P (2020) A review of remotely sensed surface urban heat islands from the fresh perspective of comparisons among different regions (invited review). Prog Electromagn Res C Pier C 102:31-46 http://dx.doi.org/10.2528/PIERC20020403

Li ZL, Tang BH, Wu H, Ren H, Yan G, Wan Z, Trigo IF, Sobrino JA (2013) Satellitederived land surface temperature: Current status and perspectives. Remote Sens Environ 131:14-37 https://doi.org/10.1016/j.rse.2012.12.008 
Mahtab-uz-Zaman QM, Mallick FH, Abdullah AQM, Ahmad J (2007) In Search of a Habitable Urban Space-Built Ratio: A Case Study of Building and Planning Regulation in Dhaka City. In Bay JH, Ong BL (eds) Tropical Sustainable Architecture: Social and Environmental Dimensions. Architectural Press (Elsevier), pp 125-147

393

Masson V, Bonhomme M, Salagnac JL, Briottet X, Lemonsu A (2014) Solar panels reduce both global warming and urban heat island. Front Environ Sci 2:14 https://doi.org/10.3389/fenvs.2014.00014

McMichael AJ, Wilkinson P, Kovats RS, Pattenden S, Hajat S, Armstrong B, Vajanapoom N, Niciu EM, Mahomed H, Kingkeow C, Kosnik M (2008) International study of temperature, heat and urban mortality: the "ISOTHURM" project. Int J Epidemiol 37(5):1121-1131 https://doi.org/10.1093/ije/dyn086

Mia B, Bhattacharya R, Woobaidullah ASM (2017) Correlation and Monitoring of Land Surface Temperature, Urban Heat Island with Land use-land cover of Dhaka City using Satellite imageries. Int J Res Geogr 3(4) http://dx.doi.org/10.20431/24548685.0304002

Oke TR (1973) City size and the urban heat island. Atmos Environ 7(8):769-779 https://doi.org/10.1016/0004-6981(73)90140-6

Oke TR (1982) The energetic basis of the urban heat island. Q J R Meteorol Soc 108(455):1-24 https://doi.org/10.1002/qj.49710845502

O'Malley C, Piroozfar P, Farr ERP, Pomponi F (2015) Urban Heat Island (UHI) mitigating strategies: A case-based comparative analysis. Sustain Cities Soc 19:222235 https://doi.org/10.1016/j.scs.2015.05.009

Pörtner HO, Peck MA (2010) Climate change effects on fishes and fisheries: towards a $\begin{array}{lllll}\text { cause-and-effect understanding. J Fish } & \text { Biol } & \text { 77):1745-1779 }\end{array}$ https://doi.org/10.1111/j.1095-8649.2010.02783.x

417 Raja DR (2012) Spatial analysis of land surface temperature in Dhaka metropolitan area. 
419 Rashid KJ, Hoque MA, Esha TA, Rahman MA, Paul A (2020) Spatiotemporal changes of

420 vegetation and land surface temperature in the refugee camps and its surrounding 421 areas of Bangladesh after the Rohingya influx from Myanmar. Environ Dev Sustain 2020:1-6 https://doi.org/10.1007/s10668-020-00733-x

423 Ryu YH, Baik JJ (2012) Quantitative analysis of factors contributing to urban heat island 424 intensity. J Appl Meteorol Climatol 51(5):842-854 https://doi.org/10.1175/JAMC-D$425 \quad 11-098.1$

426 Sahana M, Ahmed R, Sajjad H (2016) Analyzing land surface temperature distribution in 427 response to land use/land cover change using split window algorithm and spectral 428 radiance model in Sundarban Biosphere Reserve, India. Model Earth Syst Environ

430 Seto KC, Güneralp B, Hutyra L (2012) R Global forecasts of urban expansion to 2030 and direct impacts on biodiversity and carbon pools. Proc Natl Acad Sci U S A 109(40):16083-16088 https://dx.doi.org/10.1073\%2Fpnas.1211658109

Shahmohamadi P, Che-Ani AI, Maulud KNA, Tawil NM, Abdullah NAG (2011) The impact of anthropogenic heat on formation of urban heat island and energy consumption balance. Urban Stud Res 2011:1-9 https://doi.org/10.1155/2011/497524

Sobrino JA, Jiménez-Muñoz JC, Paolini L (2004) Land surface temperature retrieval from LANDSAT TM 5. Remote Sens Environ 90(4):434-440 https://doi.org/10.1016/j.rse.2004.02.003

Stewart ID, Oke TR (2012) Local climate zones for urban temperature studies. Bull Am Meteorol Soc 93(12):1879-1900 https://doi.org/10.1175/BAMS-D-11-00019.1

Tashnim J, Anwar MA (2016) Reasons and Remedies of Heat Island Phenomena for Dhaka City: A Review. In: Proceedings of the 3rd International Conference on Civil Engineering for Sustainable Development, pp 228-234

Toy S, Yilmaz S (2010) Evaluation of urban-rural bioclimatic comfort differences over a ten-year period in the sample of Erzincan city reconstructed after a heavy earthquake.

447 Trotter L, Dewan A, Robinson T (2017) Effects of rapid urbanisation on the urban 448 thermal environment between 1990 and 2011 in Dhaka Megacity, Bangladesh. AIMS 
Tzavali A, Paravantis JP, Mihalakakou G, Fotiadi A, Stigka E (2015) Urban heat island 451 intensity: a literature review. Fresen Environ Bull 4(12b):4537-4554

452 Voogt JA, Oke TR (2003) Thermal remote sensing of urban climates. Remote Sens 453 Environ 86(3):370-384 https://doi.org/10.1016/S0034-4257(03)00079-8

454 Wang F, Qin Z, Song C, Tu L, Karnieli A, Zhao S (2015) An improved mono-window 455 algorithm for land surface temperature retrieval from Landsat 8 thermal infrared 456 sensor data. Remote Sens 7(4):4268-4289 https://doi.org/10.3390/rs70404268

457 Ward K, Lauf S, Kleinschmit B, Endlicher W (2016) Heat waves and urban heat islands 458 in Europe: A review of relevant drivers. Sci Tot Environ 569-570:527-539 459 https://doi.org/10.1016/j.scitotenv.2016.06.119

460 Watkins R, Palmer J, Kolokotroni M (2007) Increased temperature and intensification of 461 the urban heat island: Implications for human comfort and urban design. Built 462 Environ 33(1):85-96 https://www.jstor.org/stable/23289474

463 Wu J, Yunus M, Ali M, Escamilla V, Emch M (2018) Influences of heatwave, rainfall, 464 and tree cover on cholera in Bangladesh. Environ Int 120:304-311 $465 \quad$ https://dx.doi.org/10.1016\%2Fj.envint.2018.08.012

466 Yankovich KS, Yankovich EP, Baranovskiy NV (2019) Classification of vegetation to 467 estimate forest fire danger using Landsat 8 images: Case study. Math Probl Eng 468 2019:1-14 https://doi.org/10.1155/2019/6296417

469 Yow DM (2007) Urban Heat Islands: Observations, Impacts, and Adaptation: Urban heat 470 islands: observations, impacts, and adaptation. Geogr compass 1(6):1227-1251 $471 \quad$ https://doi.org/10.1111/j.1749-8198.2007.00063.X

472 Zhou D, Xiao J, Bonafoni S, Berger C, Deilami K, Zhou Y, Frolking S, Yao R, Qiao Z; 473 Sobrino JA (2019) Satellite remote sensing of surface urban heat islands: Progress, 474 challenges, and perspectives. Remote Sens 11(1):48 475 https://doi.org/10.3390/rs11010048

476 Zhou D, Zhang L, Li D, Huang D, Zhu C (2016) Climate-vegetation control on the 477 diurnal and seasonal variations of surface urban heat islands in China. Environ Res 478 Lett 11(7):074009 https://doi.org/10.1088/1748-9326/11/7/074009

479 Zhou W, Qian Y, Li X, Li W, Han L (2014) Relationships between land cover and the 
480 surface urban heat island: seasonal variability and effects of spatial and thematic 481 resolution of land cover data on predicting land surface temperatures. Landsc Ecol 482 29(1):153-167 https://doi.org/10.1007/s10980-013-9950-5

483 Zhu Z, Woodcock CE (2014) Continuous change detection and classification of land 484 cover using all available Landsat data. Remote Sens Environ 144:152-171 $485 \quad$ https://doi.org/10.1016/j.rse.2014.01.011

486 


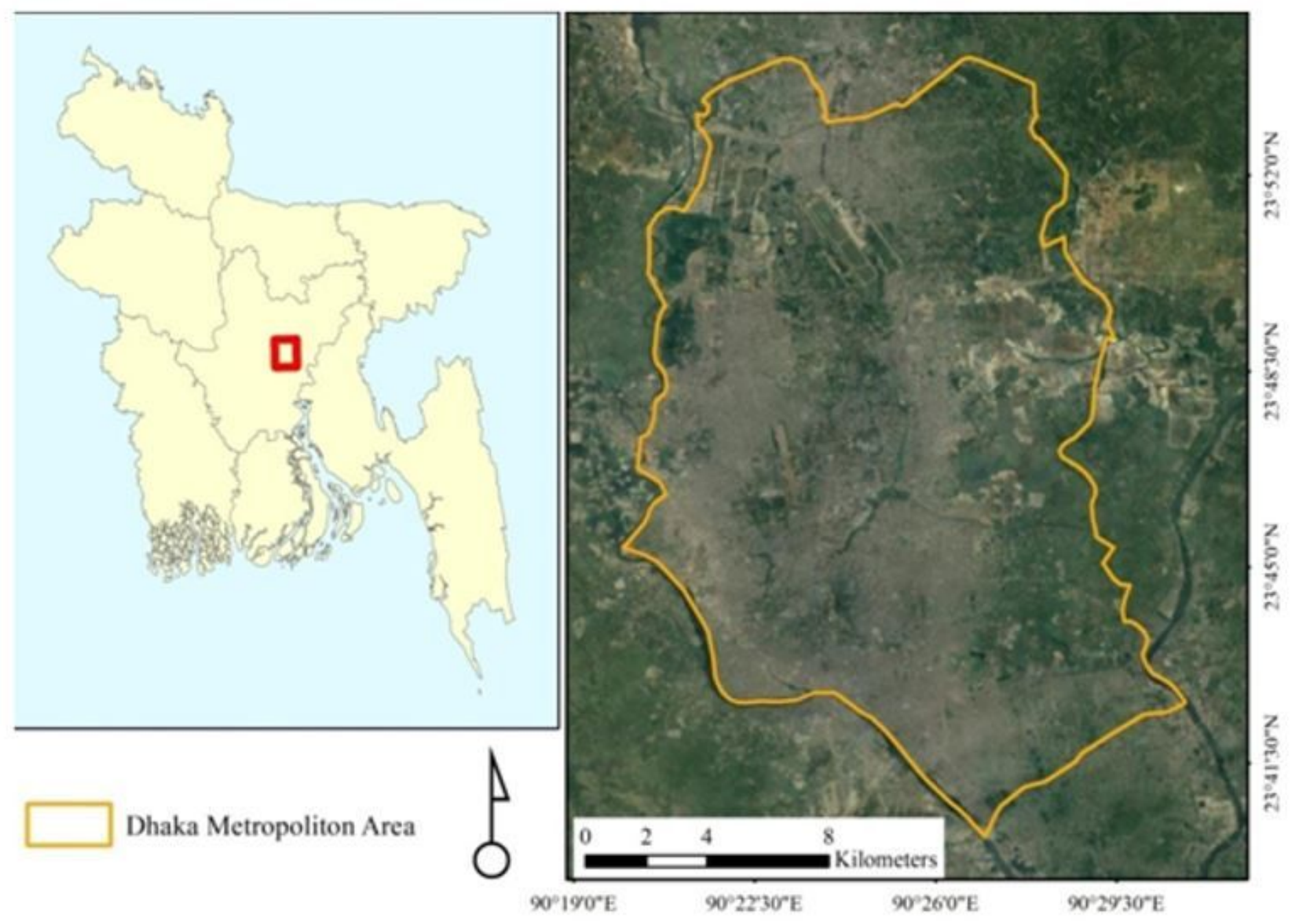

\section{Figure 1}

Study area showing administrative boundary of Dhaka Metropolitan Area (DMA) 
(a)

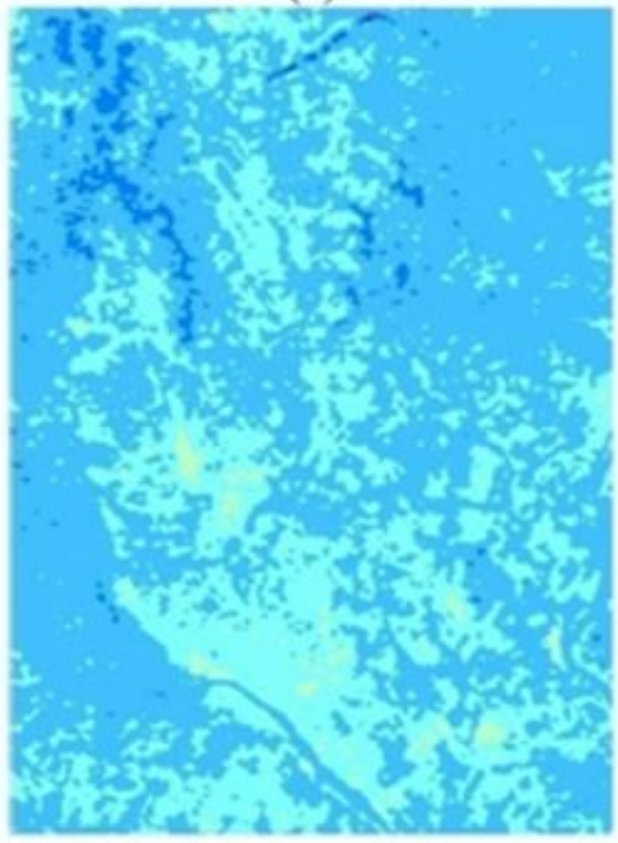

(c)

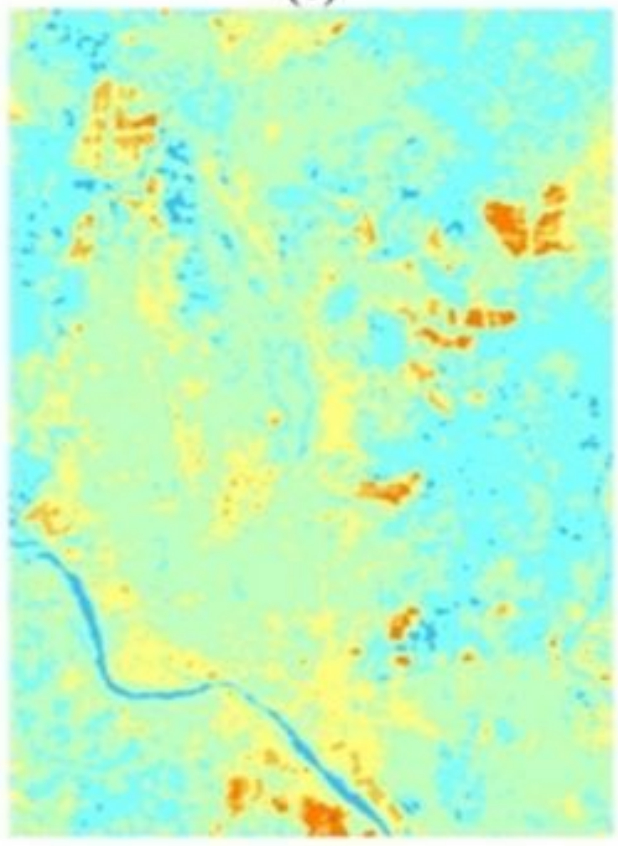

(b)

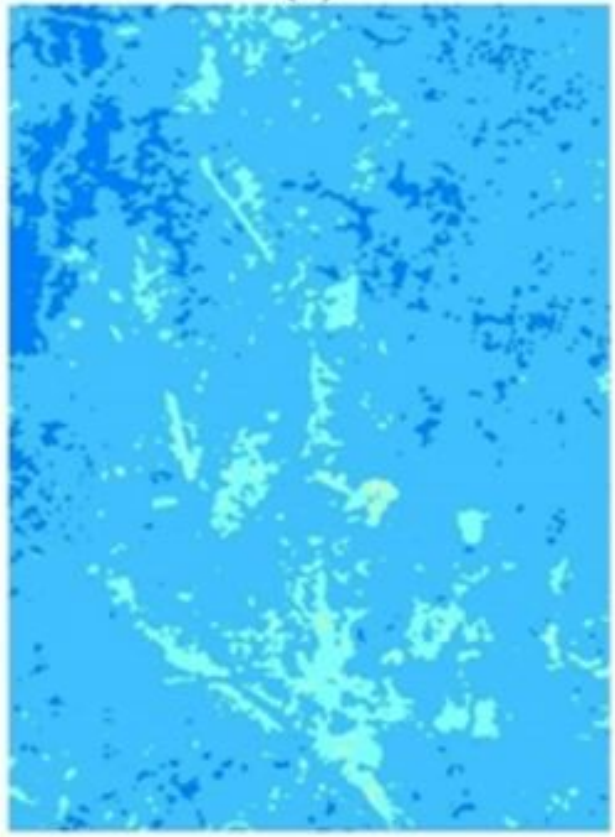

(d)

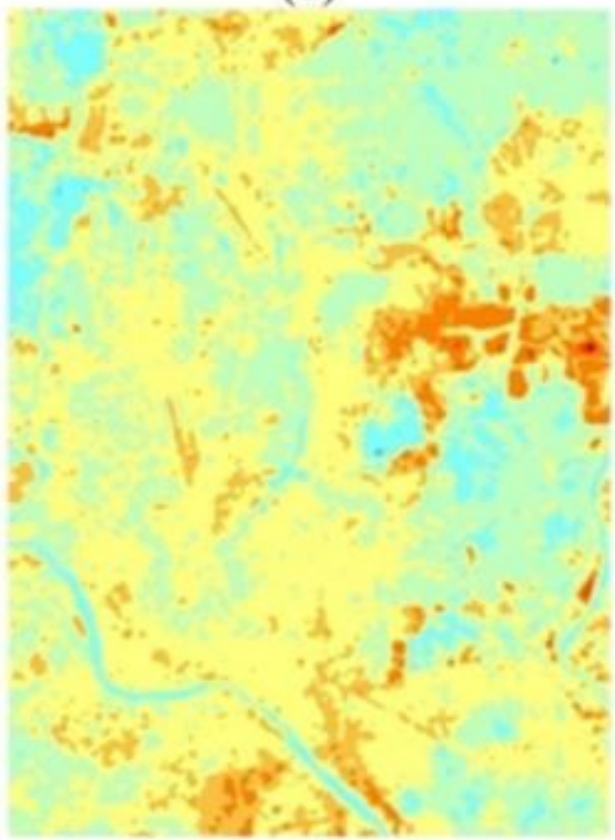

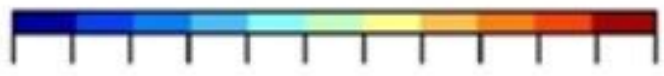

$\begin{array}{llllll}11 & 15 & 19 & 23 & 27 & 31\end{array}$

\section{Figure 2}

Spatio-temporal distribution of land surface temperature (LST) in the area where a, b, c, and d corresponds to the year 1990, 2000, 2010, and 2020 respectively 
(a)

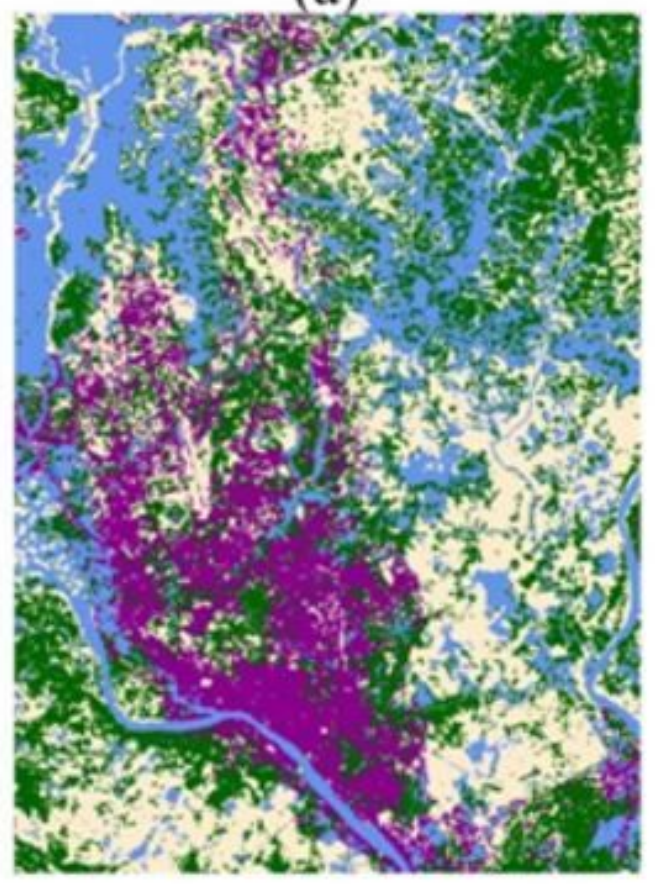

(c)

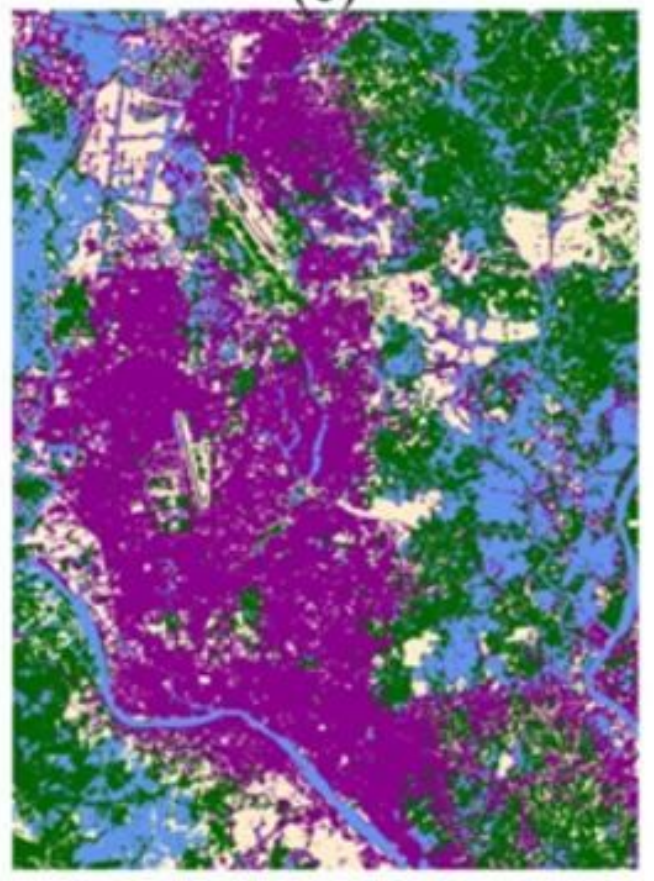

(b)

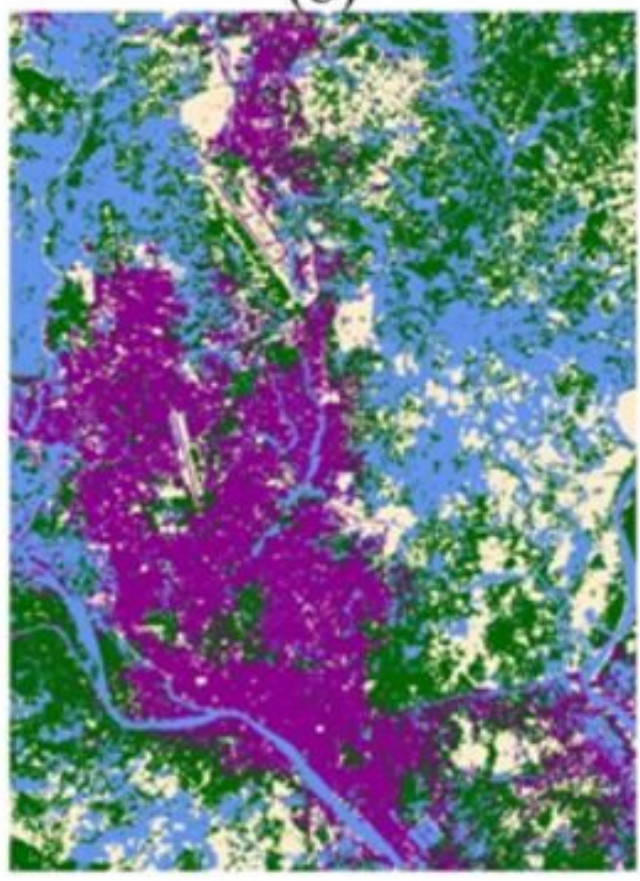

(d)

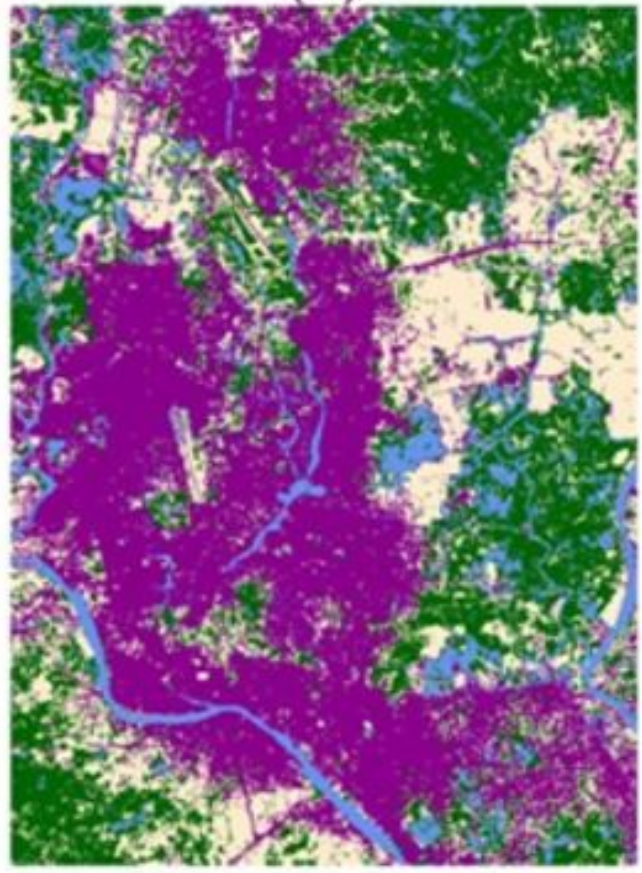

\section{$\square$ VS $\square$ WS $\square$ DS $\square$ OS}

\section{Figure 3}

LULC classification maps of Dhaka city where a, b, c, and d corresponds to the year 1990, 2000, 2010, and 2020 respectively. Also VS, WS, DS, and OS are illustrated as vegetated surface, water surface, developed surface, and open soil accordingly. 


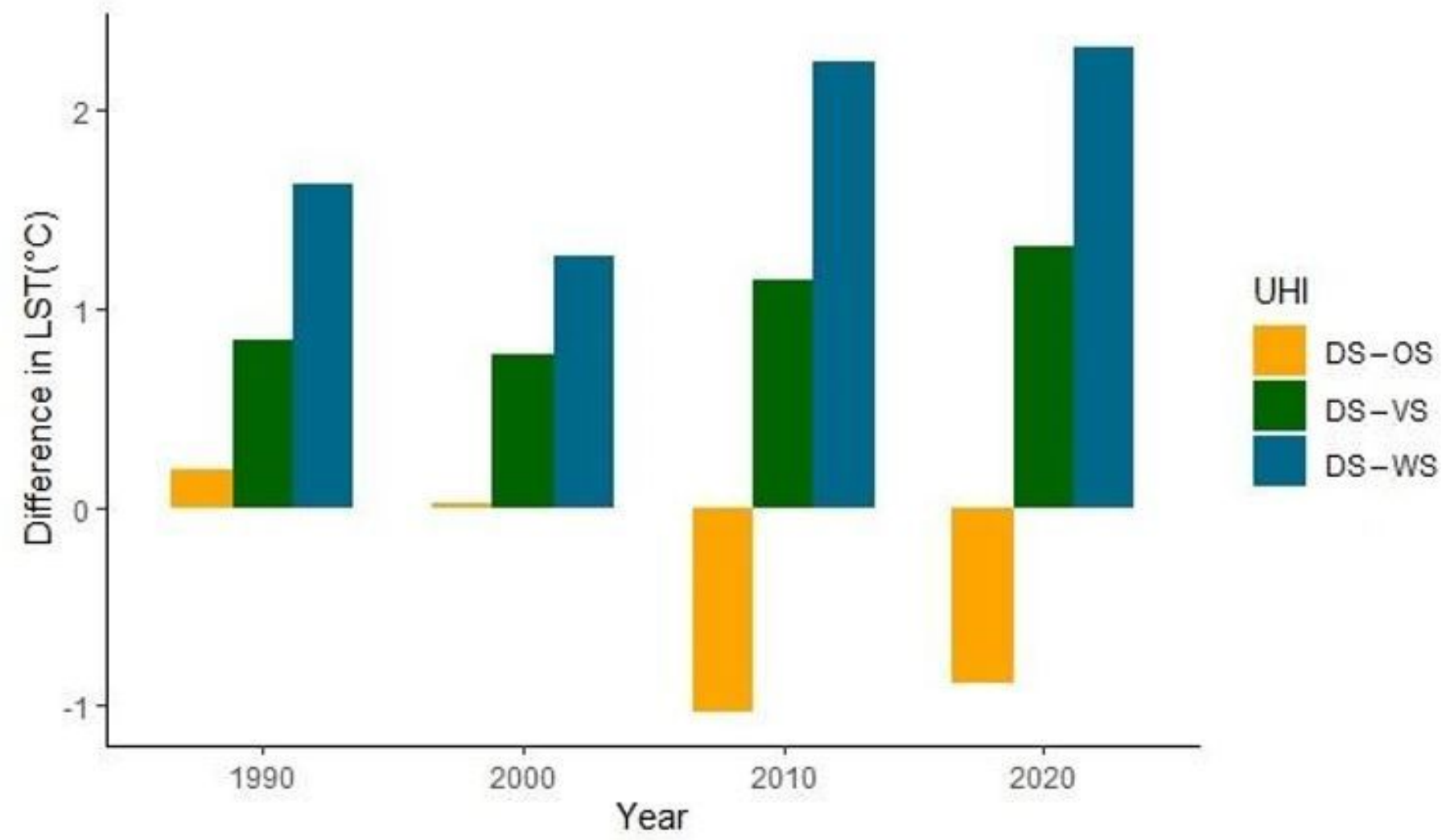

Figure 4

Difference of mean LST between developed surfaces (DS) and other LULC classes. 


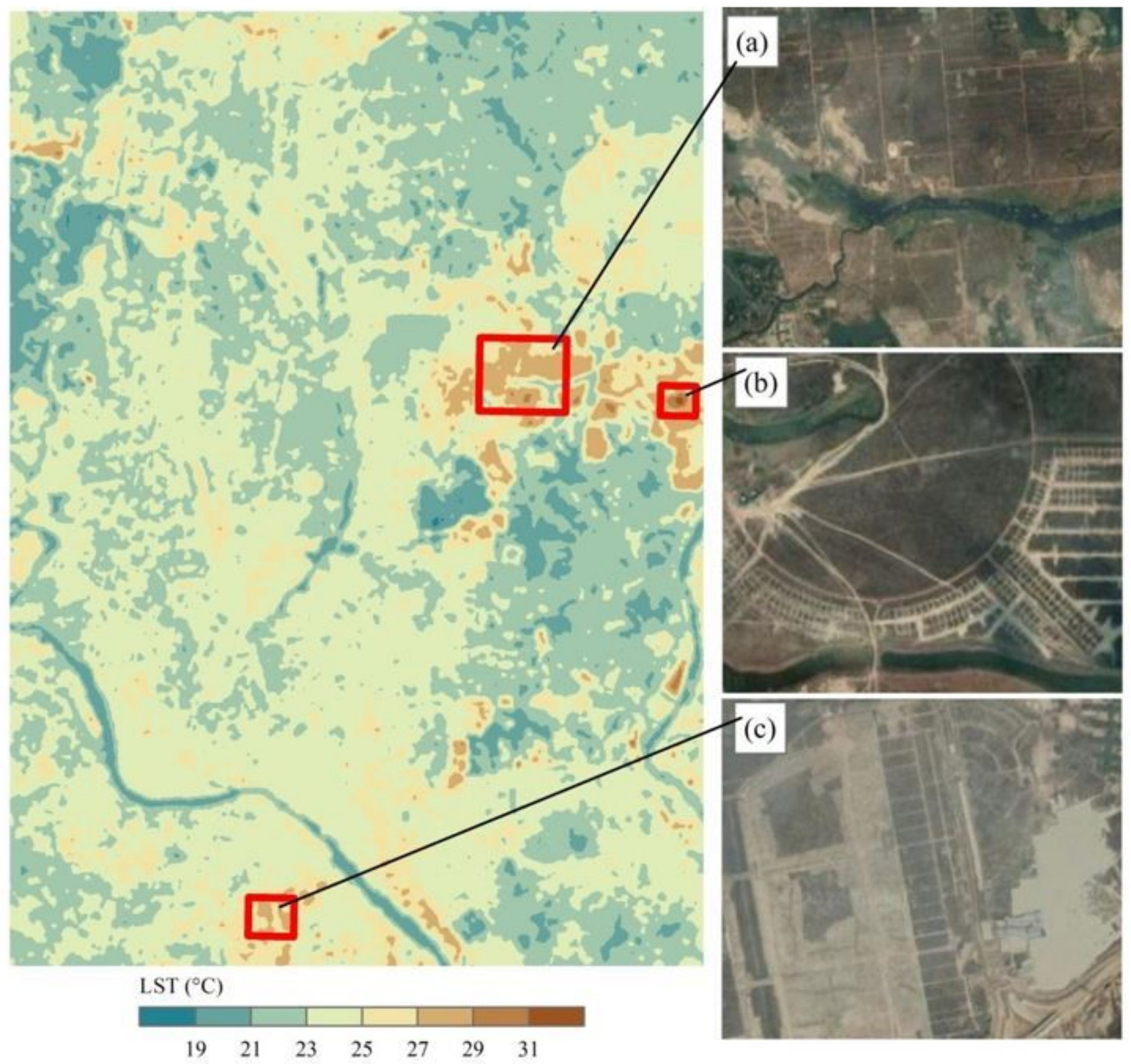

Figure 5

Patches of open soil showing extreme temperature. 
(a)

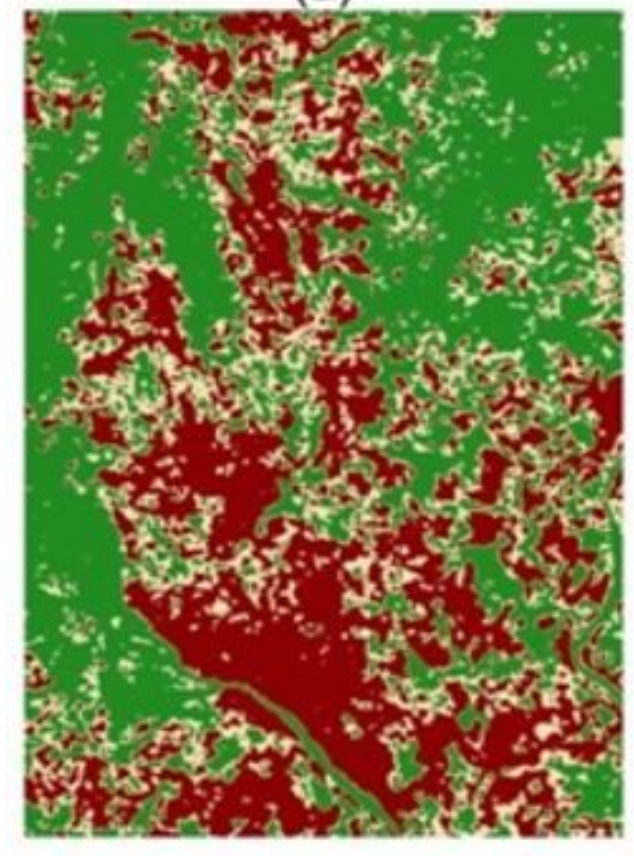

(c)

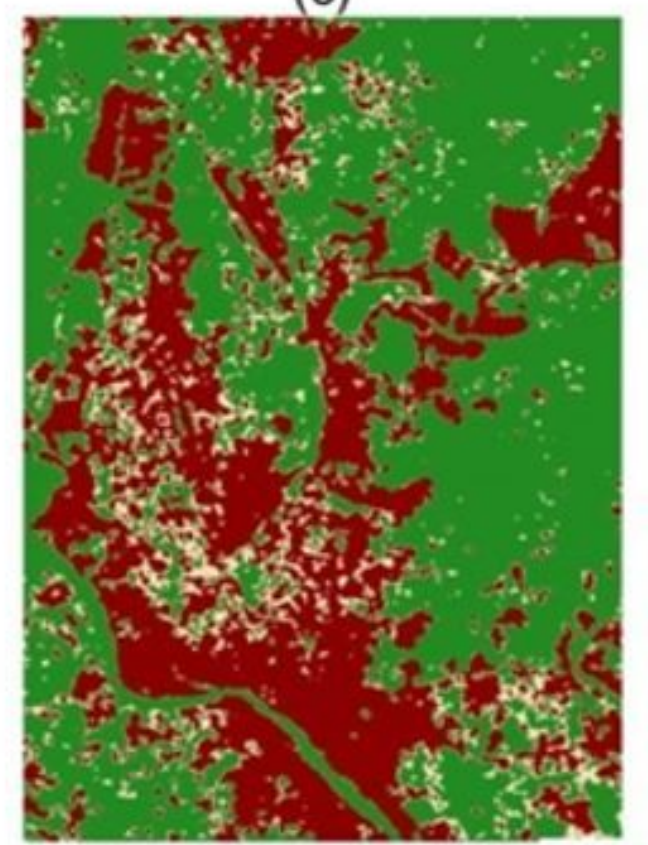

(b)

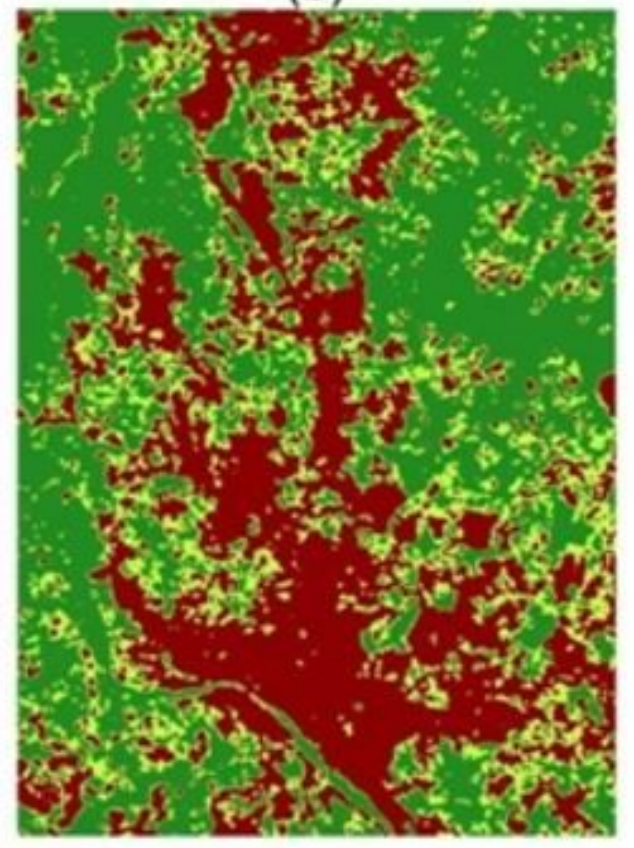

(d)

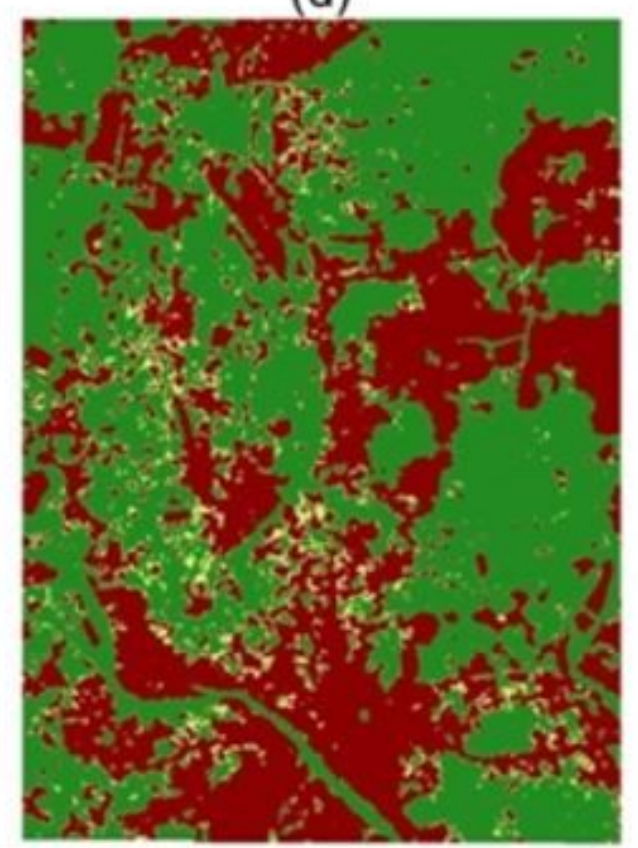

ㅁ $0.005-0.010$

\section{Figure 6}

Urban thermal field variance index (UTFVI) classification into six classes according to the Table 5 
(a)

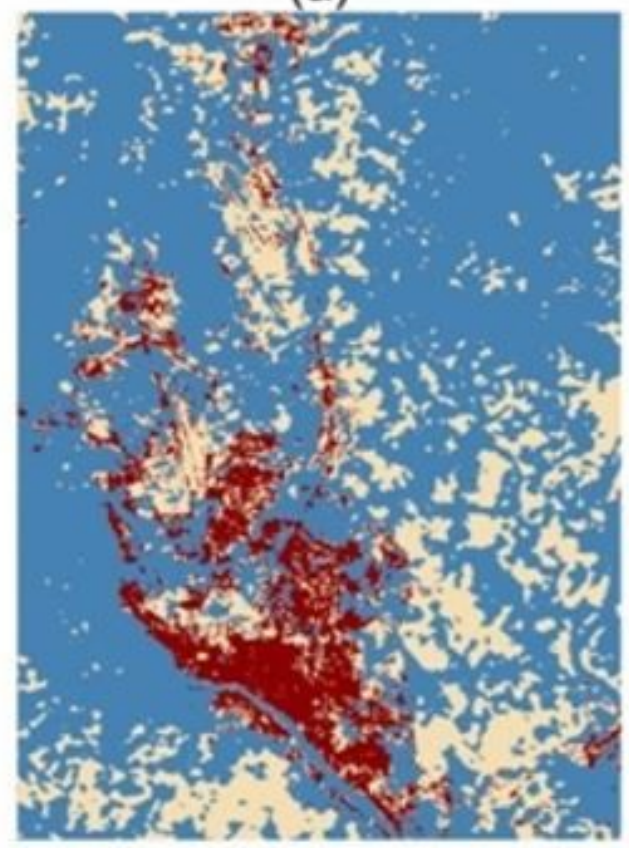

(c)

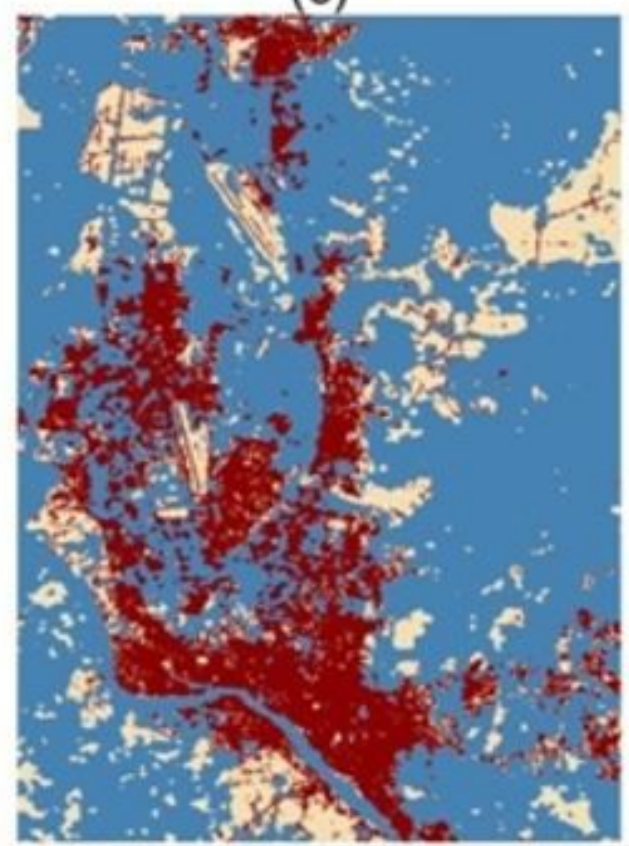

(b)

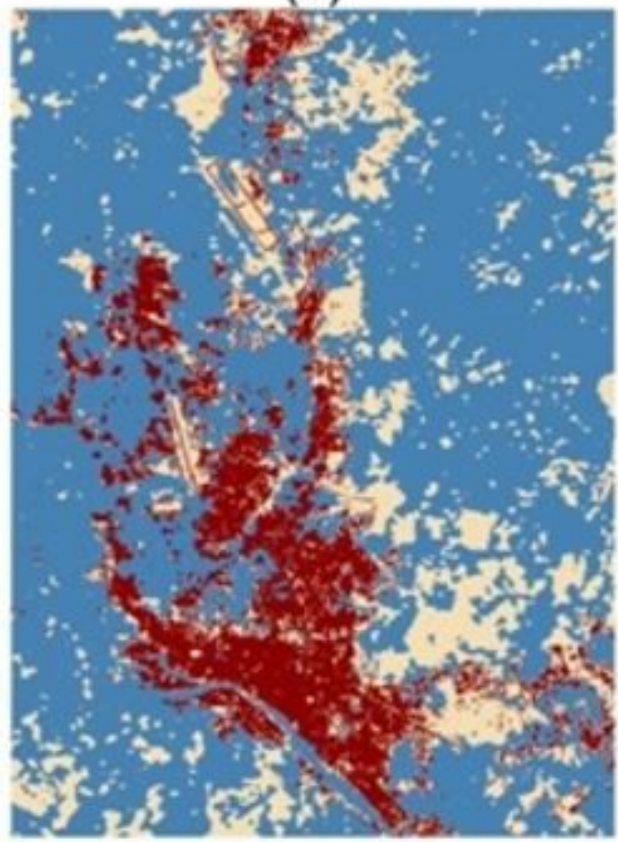

(d)

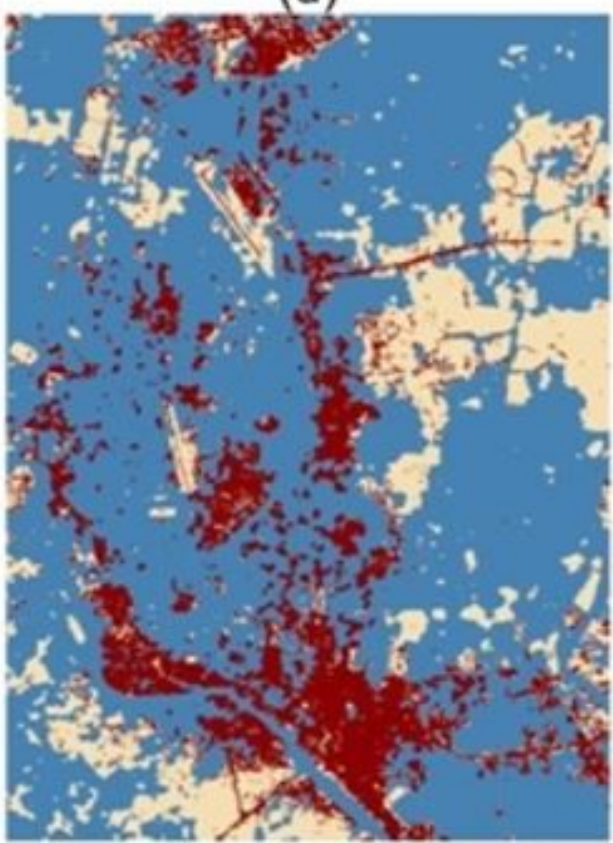

$\square$ Others area

- Below normal EEI in DS

$\square$ Below normal EEI in Non-DS

Figure 7

Comparison between LULC and UTFVI classification. 8 